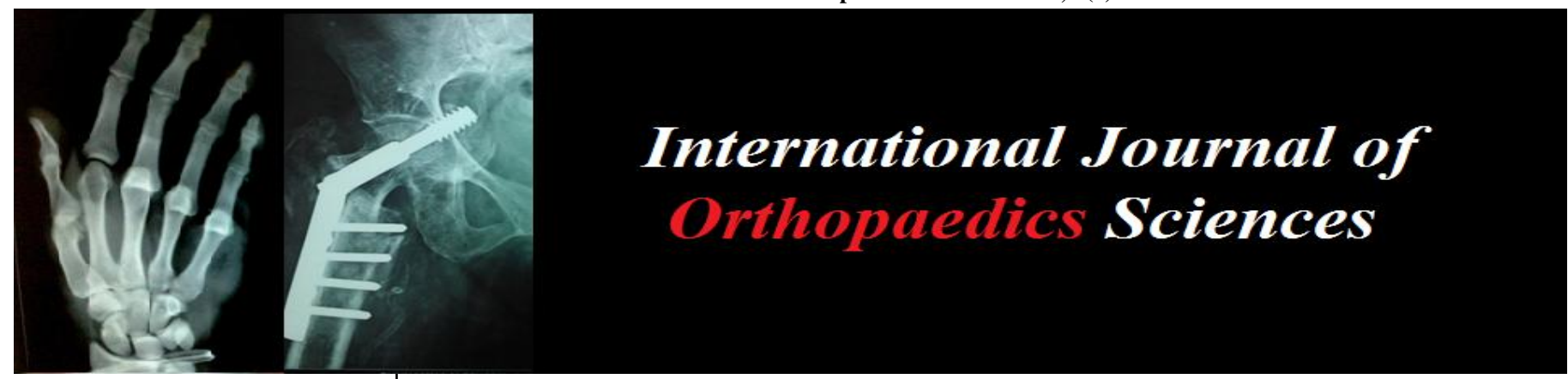

ISSN: $2395-1958$

IJOS 2018; 4(1): 303-307

(C) 2018 IJOS

www.orthopaper.com

Received: 19-11-2017

Accepted: 21-12-2017

Kanwarjit Singh Sandhu Associate Professor, Department of Orthopaedics, Government Medical College, Patiala, Punjab, India

BS Brar

Professor, Department of

Orthopaedics, Government Medical College, Patiala, Punjab, India

Dr. Amandeep Singh Bakshi Assistant Professor, Department of Orthopaedics, Government Medical College, Patiala, Punjab, India

\section{BS Bra}

Professor, Department of orthopaedics, Government Medical College, Patiala, Punjab, India

Dr. Amandeep Singh Bakshi Assistant Professor, Department of orthopaedics, Government Medical College, Patiala, Punjab, India

Dr. N Bobby

Junior Resident, Department of orthopaedics, Government Medical College, Patiala, Punjab, India

\section{Dr. Kanchan Bhardwaj}

Professor, Transfusion Medicine, Government Medical College, Patiala, Punjab, India

\section{Dr. Sanjeev Sreen}

Assistant Professor, Department of orthopaedics, Government Medical College, Patiala, Punjab, India

\section{Dr. Pardeep Kumar}

Junior Resident, Department of orthopaedics, Government Medical College, Patiala, Punjab, India

\section{Correspondence}

Dr. N Bobby

Junior Resident, Department of orthopaedics, Government Medical College, Patiala, Punjab, India Medical College, Patiala, Punjab, India

\section{A comparative effectiveness of activated platelet-rich plasma versus autologous whole blood in the management of lateral epicondylitis: A randomized clinical trial of functional outcome}

\author{
Kanwarjit Singh Sandhu, BS Brar, Dr. Amandeep Singh Bakshi, Dr. N \\ Bobby, Dr. Kanchan Bhardwaj, Dr. Sanjeev Sreen and Dr. Pardeep \\ Kumar
}

DOI: https://doi.org/10.22271/ortho.2018.v4.i1e.43

Abstract

Background: Lateral epicondylitis (tennis elbow), a familiar term used to describe myriad of symptoms around the lateral aspect of elbow mainly due to intra-tendinous degeneration assosciated with ageing, repetitive movement and vascular compromise. Activated platelet-rich plama (PRP) and Autologous whole blood (AWB) injections represent new therapeutic options for chronic tendinopathies including tennis elbow. But from the literature, no firm conclusions can be drawn about the effectiveness of PRP versus AWB or the superiority of one method over the other. Our aim of study was to compare the effectiveness and functional outcome of both modalities.

Methods: 50 patients with chronic lateral epicondylitis ( $>3$ months) with restricted ROM were included in this study and randomized into 2 groups. Group 1 was treated with a single injection of $2 \mathrm{~mL}$ of autologous PRP (4.8 times of plasma) with $1 \mathrm{ml}$ of calcium chloride as activator and group 2 with $2 \mathrm{~mL}$ of AWB injection followed by elbow-strap, stretching and strengthening exercises for both groups. Pain and functional outcomes were assessed using visual analogue scale (VAS) and NIRSCHL staging (NS) at $0,4,8$ weeks, 6 months and 12 months.

Results: Pain variables including VAS and Nirschl scores improved significantly in both groups at short and intermediate duration but on long term follow up intervals PRP showed better improvement between groups regarding pain severity, functional improvement and recurrence rates.

Conclusion: Both PRP and AWB injections are effective to treat chronic lateral epicondylitis but for longer duration the efficacy persisted with PRP seems to be superior than AWB.

Keywords: Lateral epicondylitis, Autologous whole blood injection (AWB), Platelet-rich plasma (PRP) Elbow, Injection, RCT

\section{Introduction}

- Lateral epicondylitis, or tennis elbow, is commonly encountered in orthopaedic practice. 2 ND most frequently diagnosed musculoskeletal disorder in the neck and upper extremity [1]. Incidence of between 4-7 per 1000 cases per year in general practice, peak between the ages of 35 and 54 years (mean 42 years approx) ${ }^{[2]}$. An epidemiological study reported that $87 \%$ of cases involved the dominant arm ${ }^{[3]}$. Pain and tenderness over the lateral epicondyle is the most common presentation due to result of overuse from many activities ${ }^{[8]}$. Although it is often referred to as tennis elbow, it is seen to affect non-athletes rather than athletes ${ }^{[4,5]}$.

- Histopathological studies have demonstrated that tennis elbow is not an inflammatory condition; rather, it is a fibroblastic and vascular response due to repeated microtrauma and incomplete healing response leads to angiofibroblastic degeneration ${ }^{[6]}$ especially of the origin of the ECRB(as originally described by Cyriax) ${ }^{[7]}$. Hence conservative modalities such as local injection of corticosteroid which have focused on suppressing an inflammatory process actually does not exist. It is theorised that the beneficial effects result from the bleeding caused by forcing fluid through tissue planes at high pressures ${ }^{[8]}$. 
- An injection of autologous blood and PRP has been reported to be effective for both intermediate and longterm outcomes for the treatment of lateral epicondylitis, with a significant decrease in pain. Injection of autologous blood might provide the necessary cellular and humeral mediators to induce a healing cascade due to mitomorphogenic effect of chemical modifiers carried in the blood ${ }^{[9]}$.

- Platelet rich plasma is defined as a volume of the plasma fraction of autologous blood having a platelet concentration above baseline (4 to 6 times greater than that of whole blood $(200000 / \mathrm{mm} 3)$ which have strong growth factors and granules that have critical role in the healing process of chronic injuries. The concentrations less than or greater than this amount may be ineffective or inversely lead to suppression of the healing process [10].

- The objective of this study was to evaluate the effectiveness and functional outcome of activated PRP injection vs autologous blood injection for the treatment of lateral epicondylitis (Tennis elbow).

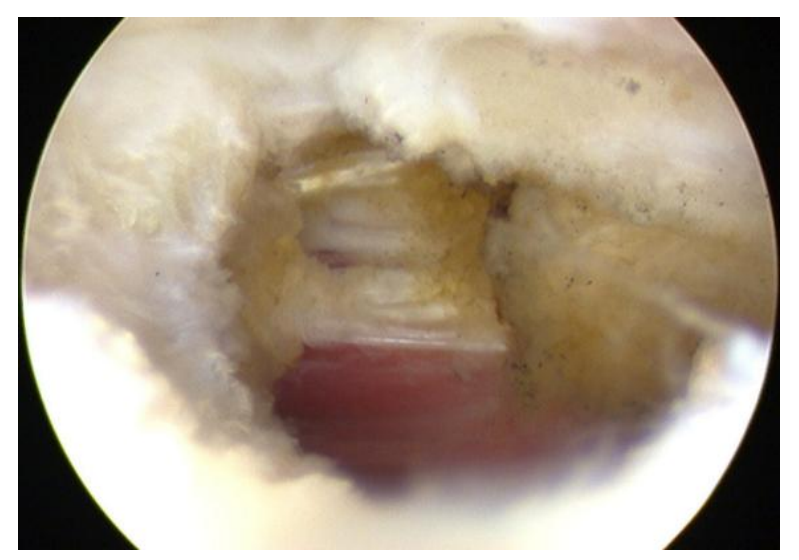

\section{Mediators of the inflammation}

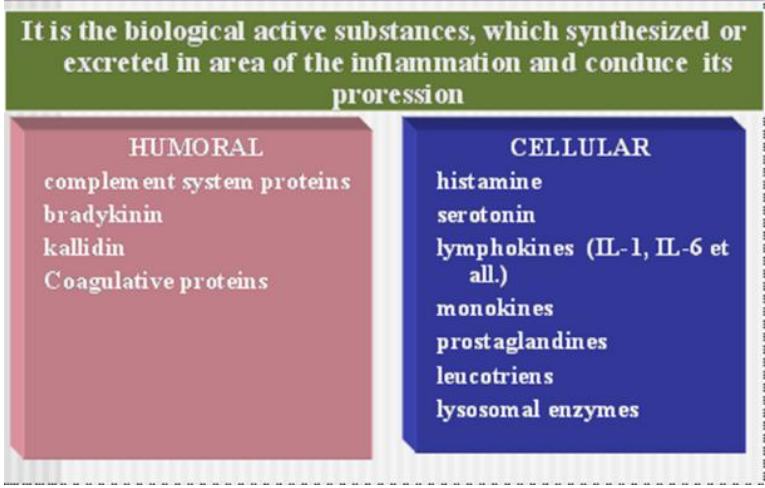

\author{
VEGF - new blood vessels \\ ECGF - new blood vessels \\ IGF - cell growth \\ PD-EGF - cell growth \\ PDGF - cell growth \\ bFGF - new collagen \\ TGF - turns stem cells into tissue
}

\section{Patients and Methods}

- This is a randomised clinical trial

- Age > 18 years and a diagnosis of lateral epicondylitis were the inclusion criteria.

- The exclusion criteria were:

1. patients received steroid injections in the three months prior to study treatment;

2. history of trauma;

3. previous surgery for lateral epicondylitis;

4. presence of other causes of elbow pain such as osteochondritis dessicans of capitellum, epiphyseal plate injuries, lateral compartment arthosis, varus instability, radial head arthritis, posterior interosseous nerve syndrome, cervical disc syndrome, synovitis of radiohumeral joint, cervical radiculopathy, fibromyalgia, osteoarthritis of elbow, or carpal tunnel syndrome.

- Patients attending outpatient department of rajindra hospital, patiala were included after a diagnosis of lateral epicondylitis was established.

- Each patient was assessed by history and clinical examination. In some cases radiological and imaging investigations were carried out to confirm the diagnosis and to identify any exclusion criteria. This included testing for tenderness over the lateral epicondyle or just distal to it, a positive Cozen's test, Mill's manoeuvre, wringing test and maudsleys test.

- Patients were allotted randomly into two groups, (1 and 2) of 25 cases each.

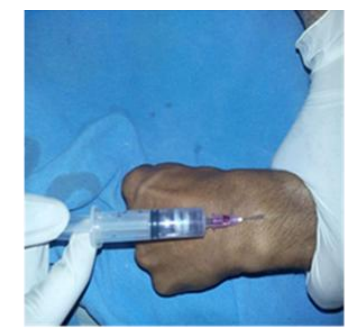

Withdrawing of Blood from the vein of ipsilateral hand
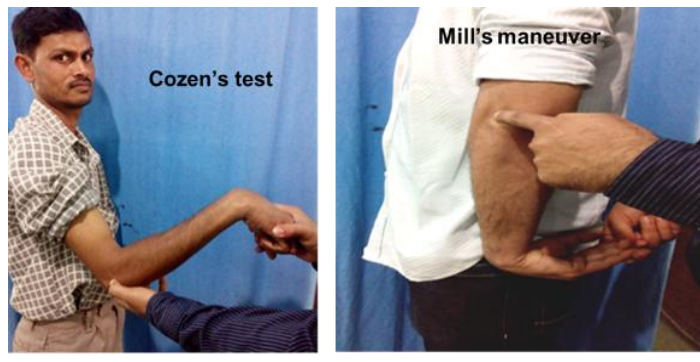

\section{Procedure}

\section{Prp Preparation}

- Group 1 was designated to receive $2 \mathrm{ml}$ of PLATELET RICH PLASMA with calcium chloride (activator)

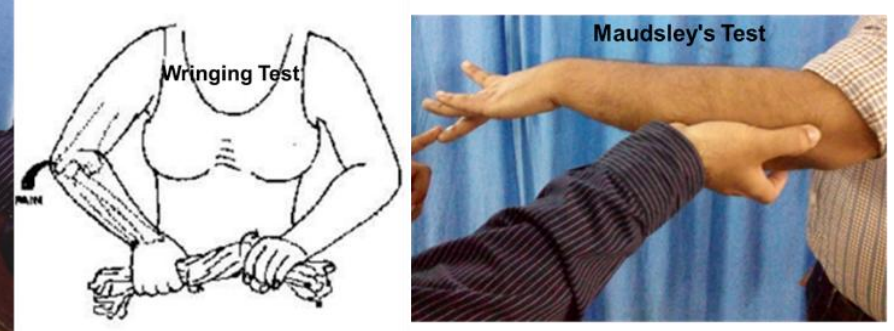

injected. For preparing $2 \mathrm{~mL}$ of PRP, $20 \mathrm{~mL}$ of blood was first collected from the cubital vein using an $18 \mathrm{G}$ needle. Then add $2 \mathrm{~mL}$ of ACD-A. One $\mathrm{mL}$ of the blood sample was sent for complete blood count. The rest of the sample 
passed two stages of centrifuge (first with $1600 \mathrm{rpm}$ for 15 minutes for separation of erythrocytes and next with $2800 \mathrm{rpm}$ for 7 minutes in order to concentrate platelets).
The final product undergoes quantification and qualification using laboratory analyzer Sysmex KX 21 and if approved, the injection was proceeded.

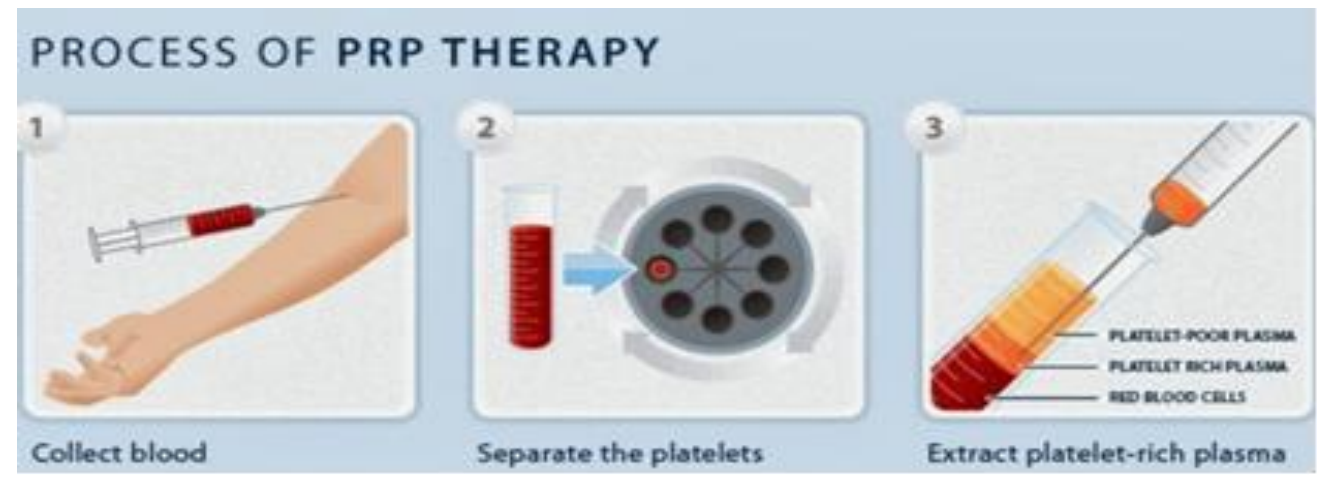

\section{Awb Preparation}

- Group 2 Patients were infiltrated with injection of $2 \mathrm{ml}$ autologous blood drawn from the contralateral upper limb vein mixed with $1 \mathrm{ml} 0.5 \%$ bupivacaine. With the patient in supine or sitting posture the elbow is flexed to $90^{\circ}$ with the palm facing down. The anatomical bony landmarks were identified. Under aseptic precautions, after local anaesthetic application the needle is introduced proximal to the lateral epicondyle along the supracondylar ridge, and gently advanced in to the undersurface of the extensor carpi radialis brevis while infiltrating by peppering technique. A small adhesive sterile dressing is applied. Patients are advised to rest the upper limb for three days, with no restriction of activity after that.

Both the VAS and the Nirschl stage were assessed by visit to the clinic pre-injection, and at one 4 weeks, 8 weeks, 4 months, 6 months and at the $12^{\text {th }}$ month final follow-up.

Statistical analysis. The ANOVA - single factor was used to compare categorical variables between the groups. A p-value $<0.05$ was considered to indicate statistical significance.

\section{Results}

Table 1.

\begin{tabular}{|c|c|c|c|}
\hline Characteristic & GROUP 1 $(n=25)$ & GROUP $2(n=25)$ & P-value \\
\hline Male : female & $10: 15$ & $8: 17$ & 1 \\
\hline Mean age (years) range & $42.6(25-61)$ & $41.1(22-64)$ & 0.63 \\
\hline Side (rt : lt) & $18: 5$ & $17: 6$ & 1 \\
\hline Dominant side (n, \%) & $20(80)$ & 19(76) & 1 \\
\hline Mean duration of symptoms (weeks) (range) & $13.4(4-44)$ & $12.12(4-54)$ & 0.75 \\
\hline \multicolumn{4}{|l|}{ Employment $(\mathrm{n}, \%)$} \\
\hline Manual & $9(36)$ & $8(32)$ & \\
\hline Non-Manual & $16(64)$ & $17(68)$ & \\
\hline
\end{tabular}

Both groups have predominantly female patients with a mean age of 42.6 years (range 25-61), \& 41.1 years (22 to 64) respectively. Both groups dominant hand affected. Mean duration around 13 weeks and non-manual workers predominantly more in both groups of our study (TABLE 1).

Table 2: Mean (SD) VAS (pain)

\begin{tabular}{|c|c|c|c|}
\hline Follow-up & Group 1 (PRP) & Group 2 (autologous blood) & p-value \\
\hline Pre- injection & $7.92(1.86)$ & $7.76(1.6)$ & 0.62 \\
\hline 4 weeks & $2.88(2.08)$ & $2.32(2.42)$ & 0.38 \\
\hline 8 weeks & $2.96(1.08)$ & $2.32(1.7)$ & 0.26 \\
\hline 4 months & $2.90(1.62)$ & $3.13(1.7)$ & 0.74 \\
\hline 6 months & $2.56(1.97)$ & $4(2.16)$ & 0.01 \\
\hline 12 months & $3.12(2.45)$ & $4.88(2.00)$ & 0.007 \\
\hline
\end{tabular}

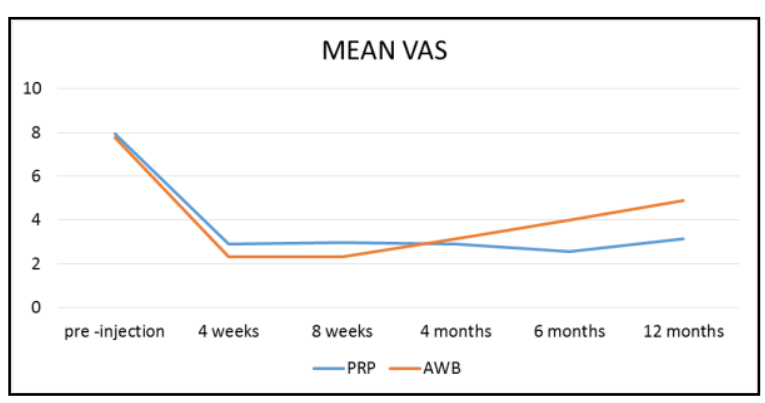

Table 3: Mean (SD) Nirschl stage (functional outcome)

\begin{tabular}{|c|c|c|c|}
\hline Follow-up & $\begin{array}{c}\text { Group 1 } \\
\text { (PRP) }\end{array}$ & $\begin{array}{c}\text { Group 2 } \\
\text { (autologous blood) }\end{array}$ & p-value \\
\hline Pre- injection & $5.72(1.24)$ & $5.48(1.12)$ & 0.42 \\
\hline 4 weeks & $2.92(1.07)$ & $2.64(1.54)$ & 0.46 \\
\hline 8 weeks & $2.2(0.81)$ & $2.04(1)$ & 0.44 \\
\hline 4 months & $1.59(1.01)$ & $2.39(1.6)$ & 0.07 \\
\hline 6 months & $1.52(1.20)$ & $2.11(1.41)$ & 0.001 \\
\hline 12 months & $1.73(1.5)$ & $2.75(1.67)$ & 0.004 \\
\hline
\end{tabular}




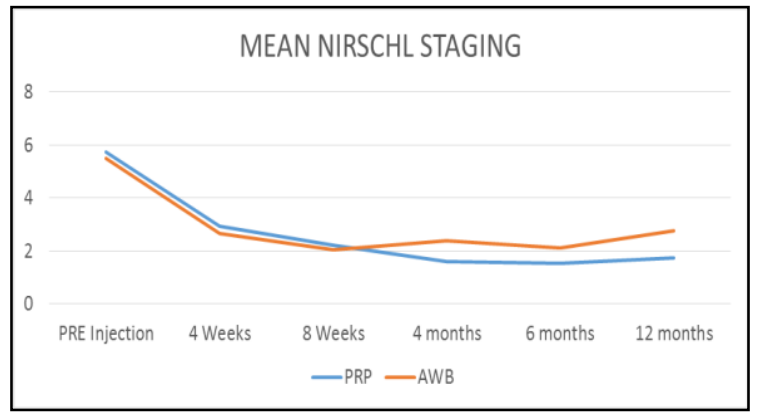

The severity of pain was measured pre-injection and after 4weeks, 8 weeks, 4 months, 6 months and at 12 months by the VAS for pain and Nirschl staging for functional outcome.

Pre-injection, the mean VAS scores for pain were similar between group 1 and group 2 (7.92 (SD 1.86) versus 7.76 (SD $1.6), \mathrm{p}=0.62$ ), as were the mean Nirschl stages (5.72 (SD 1.24) versus 5.48 (SD 1.12), $\mathrm{p}=0.42$ ). but The results of the VAS for pain and Nirschl grades followed a remarkable course over the period of follow-up, as can be seen from Table 2 and Table 3, respectively.

Initially the patients in Group 1 and 2 does not show much difference in terms of pain resolution and functional outcome at 4 weeks, 8 weeks \& 4 months. However, at 6 months, the scores for Group 2 had slowed and the VAS and Nirschl scores were significantly lower in group $1(\mathrm{p}=0.01$ and $\mathrm{p}=$ 0.001, respectively).This difference was maintained at the final 12 month follow-up also (Tables 2 and 3, Graph 1 \& 2).At 12 months after injection, the pain scores were significantly lower in group 1 compared with group 2 (VAS: 3.12 (SD 2.45) versus 4.88 (SD 2.0), $\mathrm{p}=0.007$; Nirschl grade: 1.73 (SD 1.5) versus 2.75 (SD 1.67), $\mathrm{p}=0.004)$.

Table 4.

\begin{tabular}{|c|c|c|c|c|}
\hline & \multicolumn{2}{|c|}{$\begin{array}{c}\text { PRP } \\
\text { Injection Group }\end{array}$} & \multicolumn{2}{c|}{$\begin{array}{c}\text { Autologous Blood } \\
\text { Injection Group }\end{array}$} \\
\hline $\begin{array}{c}\text { Number of } \\
\text { patients } \\
\begin{array}{c}\text { completely } \\
\text { relieved of pain }\end{array}\end{array}$ & $\begin{array}{c}4 \\
\text { Months }\end{array}$ & $\begin{array}{c}12 \\
\text { Months }\end{array}$ & 4 Months & 12 Months \\
\cline { 2 - 5 } & $(92 \%)$ & $\begin{array}{c}20 \\
(80 \%)\end{array}$ & $21(84 \%)$ & $12(48 \%)$ \\
\hline
\end{tabular}

At the 4 month assessment, 23 pts (92\%) had complete relief of pain compared to 21 patients $(84 \%)$ in group 2, but however At the 12-month follow-up, a total of 20 patients $(80 \%)$ in group 1 were completely relieved of pain, with only 12 patients $(40 \%)$ in group 2 comparitively., resulting in a rate of recurrence in this group of $42.8 \%$ (TABLE 4 ).

In group 1, 16 patients (64\%) complained of an increase in pain immediately (and during the following few days) after the injection, compared with $7(28 \%)$ in group $2(\mathrm{p}=0.009)$. Grip strength has been improved post intervention in both groups significantly. No patients reported skin atrophy, elbow stiffness, infection, reflex sympathetic dystrophy, postinjection flare, facial flushing, neurovascular damage or tendon rupture or other untoward complications.

\section{Discussion}

Lateral epicondylitis or tennis elbow has been recognised for over 100 years and is an enthesopathy of the common extensor origin is a common problem encountered in Orthopaedic practice and general Practice. The term tennis elbow is also not suitable as it is common in occupations involving repetitive forearm movements causes stress at the ECRB origin causing tendinosis. In our series none of the patients were tennis player. Majority of the treatment modalities used for its management lack scientific rationale [11]. Recently an injection of platelet rich plasma (PRP) has been reported to be effective for the treatment of lateral epicondylitis ${ }^{[12]}$. The mechanism of action of both autologous blood and platelet rich plasma is attributed to degranulation of $\alpha$ granules of platelets releasing growth factors which play a role in tissue healing and regeneration.

In this current study, Parameters like age, sex, side of elbow involved, dominance of upper limb involved, duration of symptom and type of occupation of the patients were comparable. The mean age encountered was 42.6 years and 41.1. Seyed Ahmad Raeissadat et al. (2014) in his study observed the same ${ }^{[13]}$.

Contrary to other studies (Hay et al. ${ }^{[14]}$, Edwards and Calandruccio) ${ }^{[11]}$ more number of female patients in our current study may be due more involvement with household work, a relevant etiology for the initiation of the disease. Seyed Ahmad Raeissadat et al. (2014) in his study also observed females are more involved ${ }^{[13]}$.

In almost all the studies (Verhaar et al. ${ }^{[15]}$ Seyed Ahmad Raeissadat et al. (2014), Edwards and Calandruccio) ${ }^{[11]}$ it was found that the participants had their dominant side affected more as compared to their non-dominant side.The mean duration of the condition in all 50 patients suffering from lateral epicondylitis in both groups was 13.4 weeks were comparable with similar results as in his study by Chetan et al. $(2009)^{[16]}$.

In our study more non manual workers were involved because more number of female patients were there in household work. In study conducted by Chetan et al. (2009) ${ }^{[16]}$ also showed more number of non-manual workers suffering from the condition. In this current study, both groups we have choosed patients who has restricted range of motion. $88 \%$ had full ROM and $12 \%$ had final 5 degree restriction of extension movement in PRP injection group and in autologous blood injection group $60 \%$ had ful ROM at the end of 12 month follow up

Initially the patients in Group 1 and 2 does not show much difference in terms of pain resolution \& functional scores at 4 weeks, 8 weeks \& 4 months. However, at 6 months \& 12 months both VAS \& NIRSCHL scores were significantly lower in group 1.This difference was maintained even At 12 months after injection.

Thanasas C (2011) ${ }^{[17]}$ evaluated the efficacy of PRP versus autologous blood in 28 patients with tennis elbow. Evaluation using VAS and Liverpool elbow score was performed at 6 weeks, 3 months, and 6 months concludes that PRP treatment seemed to be more effective and superior to autologous blood. Alisara Arirachakaran et al. (2015) ${ }^{[18]}$ also in their study concludes that PRP injection can improve pain and lower the risk of complications, whereas $\mathrm{AB}$ injection can improve pain, disabilities scores and pressure pain threshold but has a higher risk of complications. Lin-Chuan Chou et al. (2015) ${ }^{[19]}$ also in their meta-analysis concludes that Autologous blood injection is more effective than corticosteroid injection but not more effective than platelet-rich plasma injection in treating lateral epicondylosis. Bobin $\mathrm{Mi}$ et al. (2017) [20] metaanalytical study concludes that, considering the longterm effectiveness of PRP, we recommend PRP as the preferred option for LE. Which is in agreement with the results of our study. However, in another study by Creaney et $a l$., no differences were noticed in pain and disability up to six months after PRP or autologous blood injection in 150 patients, but there was a higher rate of conversion to surgery in the autologous blood group (20\%) versus the PRP group 
(10\%). The differences in sample size, 28 patients in Thanasas and 150 patients in Creaney may be a potential reason for differences between these two studies. Study of Dojode (2012) ${ }^{[21]}$ also showed that in autologous injection group, more number of patients suffered from post intervention pain as compared to corticosteroid injection group. Another study conducted by Ozturan et al. (2010) ${ }^{[22]}$ found that $89 \%$ of patients had no more pain after 2 days and rest $11 \%$ of patients had pain from 4 to 6 days. No studies reports regarding the PRP and related post intervention pain.

\section{Conclusion}

In conclusion, Activated PRP injection demonstrated statistically significant lower pain compared with autologous blood injection group at long-term follow-up (12 months). However preparation of platelet concentrates requires specialised equipment which is both expensive and time consuming. Autologous blood has a far easier and prompt application than PRP. Advantages of autologous blood injection are-highly acceptable, efficacious, economic, easy to carry out as outpatient procedure, devoid of potential complications such as hypoglycemia, skin atrophy, recurrences associated with corticosteroid injection. We feel with larger control trials with more than one injection and with a longer follow-up period, a fair conclusion can be drawn with regard to the efficacy of this treatment modality.

\section{References}

1. Haahr JP, Andersen JH. Physical and psychosocial risk factors for lateral epicondylitis: a population based casereferent study. Occup Environ Med. 2003; 60:322-329.

2. Hamilton PG. The prevalence of humeral epicondylitis: a survey in general practice. J R Coll Gen Pract. 1986; 36:464-465.

3. Bernhang AM. The many causes of tennis elbow. N Y State J Med. 1979; 79:1363-6.

4. Mishra A, Pavelko T. Treatment of chronic elbow tendinosis with buffered platelet-rich plasma, American Journal of Sports Medicine. 2006; 34(11):1774-1778.

5. Terry CS, Beaty JH. Shoulder and elbow injuries. In: Terry CS, ed. Campbell's operative orthopaedics. 11th ed. Vol. 3. Mosby: Elsevier. 2008, 2634-2638.

6. Iwasaki $M$, Nakahara $H$, Nakata $K$. Regulation of proliferation and osteochondrogenic differentiation of periosteum-derived cells by transforming growth factor-B and basic fibroblast growth factor. J Bone Joint Surg [Am]. 1995; 77-A:543-554.

7. Chourasia AO, Buhr KA, Rabago DP. "Relationships between biomechanics, tendon pathology, and function in individuals with lateral epicondylosis," Journal of Orthopaedic \& Sports Physical Therapy, 2013; 43:368378.

8. Balasubramaniam P, Prathap K. The effect of injection of hydrocortisone into rabbit calcaneal tendons. J Bone Joint Surg [Br]. 1972; 54-B:729-734.

9. Iwasaki $M$, Nakahara $H$, Nakata K. Regulation of proliferation and osteochondrogenic differentiation of periosteum-derived cells by transforming growth factor-B and basic fibroblast growth factor. J Bone Joint Surg [Am]. 1995; 77-A:543-554.

10. Peerbooms JC, Sluimer J, Bruijn DJ, Gosens T. Positive effect of an autologous platelet concentrate in lateral epicondylitis in a double-blind randomized controlled trial: platelet-rich plasma versus corticosteroid injection with a 1-year follow-up," American Journal of Sports
Medicine. 2010; 38(2):255-262.

11. Singh A, Gangwar DS, Shekhar. Autologous Blood versus Corticosteroid Local Injection for Treatment of Lateral Epicondylosis: A Randomized Clinical Trial. Online J Health Allied Scs. 2013; 12(2):11.

12. Connell DA, Ali KE, Ahmad M, Lambert S, Corbett S, Curtis M. Ultrasound-guided autologous blood injection for tennis elbow. Skeletal Radiol 2006; 35:371-7.

13. Raeissadat SA, Rayegani SM, Hassanabadi H, Rahimi R, Sedighipour L, Rostami K. Is platelet-rich plasma superior to whole blood in the management of chronic tennis elbow: 1 year randomized clinical trial. BMC Sports Sci Med Rehabil. 2014; 6(1):12. doi:10.1186/2052-1847-6-12

14. Hay EM, Paterson SM, Lewis M, Hosie G, Croft P. Pragmatic randomised controlled trial of local corticosteroid injection and naproxen for treatment of lateral epicondylitis of elbow in primary care. British Medical Journal. 1999; 319:964-968

15. Verhaar J, Waln KG, Van MH, Kester A, Van DLA. Local corticosteroid versus Cyriax - type physiotherapy for Tennis elbow. J Bone Joint Surg. 1996; 78(B):128132.

16. Chetan MD, Murakibhavi VG, Motimath SH. A Randomized control trial to evaluate the efficacy of autologus blood injection versus local corticosteroid injection for treatment of lateral epicondylitis. Journal of the scientific society- An official peer reviewed medical journal of KLE University's J.N. Medical College, Belgaum. 2009; 36(2):84-92.

17. Thanasas C, Papadimitriou G, Charalambidis C, Paraskevopoulos I, Papanikolaou A. Platelet-rich plasma versus autologous whole blood for the treatment of chronic lateral elbow epicondylitis:a randomized controlled clinical trial. Am J Sports Med. 2011; 39(10):2130-2134.

18. Arirachakaran, Alisara. Platelet-rich plasma versus autologous blood versus steroid injection in lateral epicondylitis: systematic review and network metaanalysis. Journal of Orthopaedics and Traumatology, 2016; 17(2):101-112.

19. Chou LC, Liou TH, Kuan YC. Autologous blood injection for treatment of lateral epicondylosis: a metaanalysis of randomized controlled trials. Phys Ther Sport. 2016; 18:68-73.

20. Mi, Bobin. Platelet rich plasma versus steroid on lateral epicondylitis: meta-analysis of randomized clinical trials. The Physician and Sportsmedicine 2017; 45(2):97-104.

21. Dojode CM. A randomised control trial to evaluate the efficacy of autologous blood injection versus local corticosteroid injection for treatment of lateral epicondylitis. Bone Joint Res. 2012; 1(8):192-7.

22. Ozturan KE, Yucel I, Cakici H, Guven M, Sungur I. Autologous blood and corticosteroid injection and extracoporeal shock wave therapy in the treatment of lateral epicondylitis. Orthopedics. 2010; 33(2):84-91. 